\title{
A FORMAÇÃO DO DIRETOR E A ESCOLA PÚBLICA: UMA NARRATIVA AUTOBIOGRÁFICA
}

\author{
JOÃO FERREIRA FILHO
}

FCT-Unesp de Presidente Prudente

YOSHIE USSAMI FERRARI LEITE

FCT-Unesp de Presidente Prudente

Neste artigo, apresento a síntese de minha dissertação de mestrado defendida em 2016, no PPGE da Unesp de Presidente Prudente/SP, tendo como linha mestra a Formação dos Profissionais da Educação, Políticas Educativas e Escola Pública. Em minha dissertação, resgatei parte de minha vida acadêmica, para refletir e tentar entender como me constituí diretor de escola e como esta construção está marcada por propósitos de trabalho democrático. Neste resgate, usei como metodologia a autobiografia, assim, olhei ao longo de minha história de vida e refleti sobre minhas vivências e práticas, na realidade da escola, primeiro como aluno, depois como professor e, finalmente, como diretor de escola pública, preocupado em realizar um trabalho com vínculo democrático, em busca de uma educação de qualidade para todos. No entanto, divido este artigo em dois grandes momentos, no primeiro, faço um breve e compacto resumo de minhas convicções acadêmicas, nas quais me baseio para pensar a educação e, no segundo, reflito sobre minha autobiografia, em um misto de sintese e releitura de minha construção como diretor de escola.

Palavras chave: Diretor de escola. Autobiografia. Gestão democrática.

\section{ABSTRACT}

\section{THE FORMATION OF THE DIRECTOR AND THE PUBLIC}

\section{SCHOOL: AN AUTOBIOGRAPHICAL NARRATIVE}

In this article I present the synthesis of my master's thesis defended in 2016 in the PPGE of Unesp of Presidente Prudente-SP, having as main line the Training of Professionals of Education, Educational Policies and Public School. In my dissertation, I rescued part of my academic life in order to reflect and try to understand how I constitute a school principal and how this construction is marked for purposes of democratic work. In this rescue I used autobiography as methodology, so I looked throughout my life history and reflected on my experiences and practices in the reality of the school, first as a stu- 
dent, then as a teacher and finally as a public school director worried about doing a job with democratic link in search of quality education for all. However, I divide this article into two great moments, in the first I make a brief and compact summary of my academic convictions, on which I base my thinking on education, and in the second I reflect my autobiography in a mixture of synthesis and re-reading of my construction as school principal.

Keywords: School director. Autobiography. Democratic management.

\section{RESUMEN LA FORMACIÓN DEL DIRECTOR Y LA ESCUELA PÚBLICA: UNA NARRATIVA AUTOBIOGRÁFICA}

En este artículo presento la síntesis de mi disertación de maestría defendida en 2016 en el PPGE de la Unesp de Presidente Prudente-SP, teniendo como línea maestra la Formación de los Profesionales de la Educación, Políticas Educativas y Escuela Pública. En mi disertación rescaté parte de mi vida académica para reflexionar e intentar entender cómo me constituye director de escuela y cómo esta construcción está marcada con propósitos de trabajo democrático. En este rescate usé como metodología la autobiografia, así, miré a lo largo de mi historia de vida y reflexioné sobre mis vivencias y prácticas en la realidad de la escuela, primero como alumno, después como profesor y finalmente como director de escuela pública preocupado en realizar un trabajo con el vínculo democrático en busca de educación de calidad para todos. Sin embargo, dividido este artículo en dos grandes momentos, en el primero hago un breve y compacto resumen de mis convicciones académicas, en las que me baso para pensar la educación y, en el segundo, reflejo mi autobiografía en un mixto de síntesis y relectura de mi construcción como director de escuela.

Palabras clave: Director de escuela. Autobiografia. Gestión democrática.

\section{Introdução}

Este artigo é a síntese de minha dissertação de mestrado, que teve como objetivo procurar entender como me constituí diretor de escola com tendências a práticas democráticas. Persegui este objetivo, vendo e revendo minha própria trajetória de vida e as experiências que travei com as escolas públicas pelas quais passei como aluno, como professor e como diretor de escola. Nestas lembranças de vida, procurei rememorar as figuras dos diretores de escola e as possiveis marcas que estes deixaram impressas em minha memória, para entender até que ponto estas fazem parte do diretor de escola que sou hoje.

Para me situar historicamente e demarcar o lugar do qual falava, percorri parcialmente a história da educação no Brasil.

Desta caminhada, entendo ser preciso marcar que, desde o início, a educação brasileira 
esteve a serviço da classe de mando:

[...] desanimador o saldo das medidas educativas nos primeiros tempos da história do Brasil, com um ensino elementar precaríssimo e o acesso à escola como privilégio de uma minoria, fato que, sem dúvidas, vai marcar a sociedade brasileira. (DI GIORGI; LEITE, 2010, p. 309-310)

Este quadro desanimador só mostrou sinais de mudança a partir de 1960, quando pudemos observar indícios da democratização do ensino público, marcados pela progressiva extensão das oportunidades de acesso à escola, para todos os segmentos da sociedade. Assim, como nos salientou Beisiegel (2006), a democratização da educação precisa passar, primordialmente, pela garantia do atendimento quantitativo de alunos nas escolas públicas.

Ideal que também é compartilhado por Cortella (1998) e Libâneo (2015), que entendem a democratização do ensino a partir da garantia do acesso de todas as crianças e adolescentes aos bancos escolares, na permanência destes ao longo do período de escolaridade, e na excelência da qualidade do ensino a eles oferecido.

Nóvoa (1995) lembra que o processo de democratização da educação é lento e não acompanha a rapidez das informações da sociedade, por isso é urgente que a escola repense seu tradicional papel de mera transmissora de conhecimentos aos alunos. Ao que entendo ser igualmente necessário que se repense e altere o papel e a função do diretor e demais profissionais da educação diante desse novo cenário.

0 antigo modelo de educação, de escola e de gestão escolar, precisa ser repensado, há que se ir além do ensino de "leitura, escrita, cálculo e outras noções elementares" e se passe a explicitar "os conceitos, os conteúdos ideológicos que estão sendo transmitidos" (BEISIEGEL, 2006, p. 21).

Não se trata de descartar o antigo modelo de educação e de escola, mas em remodelar, reorganizar, repensar, para melhor atender a esta nova camada social que, agora, merecidamente, ocupa seu lugar nos assentos escolares.

Estamos vivendo um período histórico de transição de valores, costumes e hábitos que fazem com que a escola repense seu papel diante da sociedade que se impõe. [...] Diante deste quadro de mudanças e transformações a escola, como instituição social, representa o espaço propício para mudanças significativas; ela pode e deve ser um centro de debates, de discussões que propiciem infinitos momentos de reflexão de todos que dela participam, quer direta ou indiretamente; é o espaço que pode formar pessoas críticas capazes de entender o seu papel enquanto sujeitos históricos e transformadores na sociedade; que passem a compreender criticamente a sociedade onde vivem e reflitam sobre sua atuação nessa sociedade. (FERREIRA FILHO, 2016, p. 18-19)

No entanto, este não é o trabalho que deve ser realizado por apenas uma pessoa ou por um grupo de pessoas, é o trabalho de toda a comunidade escolar, com seus atores e autores, é uma parceria de "co-responsabilidade dos diferentes actores educativos (professores, alunos, pais, comunidades), incentivando os espaços de participação e os dispositivos de partenariado ao nível local" (NÓVOA, 1995, p. 24).

A figura do diretor de escola é relevante nesta mudança de postura da gestão escolar, pois, investido culturalmente de um papel centralizador e de poder, pode abrir mão deste e buscar a parceria e a participação de todos os demais participantes do trabalho pedagógico, gerando a "co-responsabilidade" e o sentimento de pertencimento necessários à eficácia do processo educativo. Paro (2010) já afirmou que é:

A 'coordenação' do esforço de funcionários, professores, pessoal técnico-pedagógico, alunos e pais, fundamentada na participação coletiva, é de extrema relevância na instalação 
de uma administração democrática no interior da escola. É através dela que são fornecidas as melhores condições para que os diversos setores participem efetivamente da tomada de decisões, já que estas não concentram mais nas mãos de uma única pessoa, mas na de grupos ou de equipes representativos de todos. (PARO, 2010, p. 245)

Entendo que esta é a mesma gestão democrática já anunciada pela Constituição Federal de 1988 - CF (BRASIL, 1988), reafirmada pela Lei de Diretrizes e Bases da Educação Nacional no 9.394/96 - LDB (BRASIL, 1996) e exigida pelo Plano Nacional da Educação - PNE (BRASIL, 2014), Lei no 13.005 , de 25/6/2014, mas que ainda se mantém como meta a ser alcançada.

Mas, sendo a gestão democrática a conjugação do trabalho de todos os que participam direta e indiretamente da escola, não basta a lei, são necessárias a vontade, a tomada de decisão e a mudança de postura destes em conjunto à vontade, tomada de decisão e mudança de postura do próprio diretor de escola. É esta "coordenação" de esforços que fará a diferença na "instalação de uma administração democrática" (PARO, 2010, p. 245)

No entanto, não podemos nos esquecer que:

No caso da escola, a organização e a gestão referem-se ao conjunto de normas, diretrizes, estrutura organizacional, ações e procedimentos que asseguram a racionalização do uso dos recursos humanos, materiais, financeiros e intelectuais assim como a coordenação e o acompanhamento do trabalho das pessoas. [...]

Dessa definição geral são extraídas duas consequências importantes. A primeira é que as formas de organização e gestão são sempre meios, nunca fins, [...]. A segunda, é que conceitualmente, a gestão faz parte da organização, mas aparece junto a ela por duas razões: a) a escola é uma organização em que tanto seus objetivos e resultados quanto seus processos e meios são relacionados com a formação humana, ganhando relevância, portanto, o fortaleci- mento das relações sociais, culturais e afetivas que nela têm lugar; b) as instituições escolares, por prevalecer nelas o elemento humano, precisam ser democraticamente administradas, de modo que todos os seus integrantes canalizem esforços para a realização de objetivos educacionais, acentuando-se a necessidade da gestão participativa e da gestão de participação. (LIBÂNEO; OLIVEIRA; TOSCHI, 2012, p. 411-412, grifo dos autores)

Com isso, percebemos que as escolas públicas estaduais não são entidades isoladas, fazem parte de um sistema composto por princípios, normas e regras gerais, que precisam ser conhecidas e gerenciadas para assegurar a "racionalização e o uso" de recursos. Outra conclusão apresentada por Libâneo, Oliveira e Toschi (2012), e que partilhamos, é que "as formas de organização e gestão são sempre meios, nunca fins"; portanto, embora haja a necessidade de se discutir a gestão, esta é feita para melhor se atingir o fim último da escola, isto é, a educação de qualidade para todos. Ainda das conclusões de Libâneo, Oliveira e Toschi (2012), partilhamos e ressaltamos que a escola é uma "organização" que tem por propósito a formação humana, por isso precisa ter fortificadas as suas "relações sociais, culturais e afetivas", presentes em seu dia a dia e, porque o "elemento humano" deve prevalecer nas relações escolares, as escolas "precisam ser democraticamente administradas", imperativo que justifica e fortalece a conjugação de ideias e esforços de todos, tendo em vista a qualidade do ensino.

Embora as escolas estejam sob o julgo de um sistema que direciona sua organização e a sua gestão, Paro (2011) nos lembra que o diretor tem uma tarefa desafiante no cotidiano das escolas públicas, principalmente as estaduais, onde desempenha o papel de representante legítimo do Estado e tem a tarefa de executar as incumbências que the são exigidas diariamente, por intermédio da diretoria de ensino 
e ou da própria Secretaria de Estado da Educação (SEE/SP).

Será, portanto, muito útil aos objetivos da gestão participativa que os professores compreendam os processos de tomadas de decisões do Estado e do sistema educativo, entendendo que a escola não está isolada do sistema social, político e cultural, como, ao contrário, não só ela depende das estruturas sociais, como também as práticas de imposição normativa podem estar retirando dos professores a autonomia de assumir suas próprias decisões. Por outro lado, os instrumentos normativos e as diretrizes curriculares e organizativas não podem ser uma camisa de forças para as escolas. Podem, sim, ser objeto de interpretação, ser rediscutidos, ser apenas parcialmente acatados e até propiciar as decisões mais apropriadas ao contexto das escolas. (LIBÂNEO; OLIVEIRA; TOSCHI, 2012, p. 418)

Alinhados ao pensamento de Paro (2011), quanto ao fato de o diretor ser o representante legal do Estado, estão Libâneo, Oliveira e Toschi (2012), que também acreditam que isso não quer dizer que ele precise concordar e fazer tudo de acordo com o que the é pedido, mas pode e tem obrigação, ética e pedagógica, de agir visando o bem comum dos que usufruem dos serviços educacionais.

Neste sentido, na escola (exemplo privilegiado por esta perspectiva) ora se ligam objetivos, estruturas, recursos e actividades e se é fiel às normas burocráticas; ora se promove a sua separação e se produzem regras alternativas; ora se respeita a conexão normativa, ora se rompe com ela e se promove a desconexão de facto. (LIMA, 2011, p. 51, grifos do autor)

Assim, reforço a necessidade de se ter uma gestão democrática. Quando, para o bem comum dos educandos, se faz necessário tomar decisões que vêm na contramão do legalmente estabelecido, é a força do coletivo que o faz e justifica o enfrentamento. O olhar múltiplo e "co-responsável" do coletivo escolar percebe suas necessidades e exigências e, com pro- priedade, produz suas "normas alternativas", com a finalidade de assegurar a "formação humana".

Após transcorridos mais de 20 anos de LDB, a gestão democrática ainda é causa de discussões e debates. Percebemos, pelas discussões que travamos até aqui, que não é fácil praticar a gestão democrática; ela requer um exercício constante de todos que compõem a escola. Vemos também, pelas falas e práticas de colegas diretores, que a democracia "é boa no papel". No entanto, sempre esteve entre as minhas preocupações; entendo o trabalho, qualquer que seja ele, como sendo o trabalho coletivo. Por isso, o caminho metodológico escolhido para retratar minha formação de diretor de escola, preocupado em estabelecer uma gestão que, com caráter democrático, atendesse de forma qualitativa a educação, foi a autobiografia.

Pesquisei nos bancos de dados das teses e dissertações das universidades públicas do Estado de São Paulo e encontrei poucos trabalhos com temática e metodologia semelhantes à escolhida por mim para desenvolver minhas experiências e, juntamente com minha orientadora, entendemos ser este um caminho fértil a ser trilhado.

Dos trabalhos encontrados, apenas dez mostraram alguma similaridade com o que buscava em minha pesquisa, mas em nenhum deles percebi o diretor narrando sua própria prática gestora e este foi o diferencial que procuramos marcar nesta pesquisa, pois tínhamos como claro que "[...] por ser o narrador, concomitantemente, sujeito e objeto da pesquisa, ele desenvolve um mais apurado conhecimento de si, num movimento constante de construção/reconstrução da identidade pessoal e profissional" (ABRAHÃO, 2008, p. 173). Dessa forma, acreditei ser este o caminho mais apurado para encontrar o "eu" que buscava em minha formação como diretor. É esta subjetivi- 
dade presente na metodologia das narrativas que nos interessava, pois cremos que ela completa o entendimento do sujeito, dos "eus".

Josso (2006) nos lembra que:

Em resumo o material biográfico [...] permite aos autores que desejam isso e mediante um esforço de reflexividade, responder a um conjunto de macro-questões tais como:

- Sobre o que eu apoio para pensar ser aquele ou aquela que penso ser e quero tornar-me? Como me configurei como sou? E como me transformei?

- Sobre o que me baseio para pensar o que penso? De onde vêm as ideias que acredito serem minhas?

- Sobre o que me apoio para fazer o que foço da maneira como faço e/ou pretendo fazer? Com quem e como aprendi meu "saber-fazer" em suas dimensões técnicas, pragmáticas e relacionais?

- Sobre o que me apoio para dizer o que digo (a escolha das técnicas, abordadas nos relatos) da maneira como o enuncio (de onde vem o meu linguajar e o meu vocabulário). De onde vem minha inspiração, minhas aspirações e meus desejos? (2006, p. 25-26)

Há nestas indagações de Josso (2006) um questionamento filosófico milenar que ainda hoje se mantém vivo em nossas buscas existenciais. Quais são as crenças que subjazem ao que penso, falo e faço, e como e sob quais circunstâncias eu as adquiri e me transformei? Quer tenhamos participado do "mundo das ideias" platônico, quer abstraído conceitos a partir das experiências vividas, não nascemos prontos, passamos por um processo de formação. Por isso, meus pensamentos, meus dizeres, meus fazeres, são frutos coletivos quer das reminiscências platônicas, quer das experiências aristotélicas, quer ainda do materialismo histórico.

Não acredito em acaso, mas em construção, e buscar essa ou essas fontes do meu/ meus "eus" é a angústia do homem, ao que as narrativas têm muito a contribuir, quando ul- trapassam o dito/narrado e buscam a subjetividade que jaz por entre as linhas do manifestado/narrado.

Ainda:

É preciso reconhecer que muitas de nossas lembranças, ou mesmo de nossas ideias, não são originais: foram inspiradas nas conversas com os outros. Com o correr do tempo, elas passam a ter uma história dentro da gente, acompanhando nossa vida e são enriquecidas por experiências e embates. Parecem tão nossas que ficaríamos surpresos se nos dissessem o seu ponto exato de entrada em nossa vida. Elas foram formuladas por outrem, e nós, simplesmente, as incorporamos ao nosso cabedal. $\mathrm{Na}$ maioria dos casos creio que este não seja um processo consciente. (BOSI, 2015, p. 407, grifo da autora)

Nesta perspectiva de busca do "eu" e das histórias "inspiradas nas conversas com os outros" é que apresento a história de um diretor de escola preocupado, não apenas com o modo de gerir a escola, mas igualmente com a qualidade de ensino oferecida por ela. Esta narrativa autobiográfica está recheada de lembranças que já não são só minhas, mas são lembranças de vidas divididas, repartidas.

São histórias partilhadas que têm como característica singular a valorização da posição do pesquisador. Por isso, eu diretor de escola - autor/ator - olho para minha prática no chão da escola e procuro entender como me constituí no diretor que sou. Procuro entender como:

[...] As trajetórias narradas proporcionam a construção de sentido de uma vida - a narração dessa trajetória não é resultante do que realmente ocorreu em termos de experiências e aprendizagens, mas é resultante da organização desses elementos como um argumento com dimensão temporal, espacial e de múltiplas relações sociais. (ABRAHÃO, 2008, p. 172-173)

Assim, minha dissertação obedeceu a trajetória do "sentido de (minha) vida". Esta foi 
pensada e sintetizada sobre quatro eixos básicos de minhas vivências acadêmicas: eu, enquanto aluno que observo a escola; eu, enquanto professor que trabalho e, de certa forma, faço a escola; eu, como diretor que busquei usar de práticas democráticas em minhas gestões e fui me constituindo diretor de escola e, finalmente, eu, diretor que procura organizar sua prática à luz dos comentários, avaliações e discussões geradas a partir do contato com a comunidade escolar.

Em cada um desses eixos, procurei resgatar a história social do momento vivido; igualmente tentei resgatar os fatores históricos da educação, com suas mudanças e implicações no dia a dia da escola, e sua influência na vida do aluno, trazendo, para apoiar e significar a reflexão, alguns pensadores que marcaram época e que contribuíram para elucidar, não só a educação como um todo, mas principalmente o papel do diretor em todo o processo escolar.

\section{Percepções de meus "Eus" na constituição do diretor de escola}

A partir da reconstituição de minhas vivências históricas e culturais, de minhas experiências como aluno, como professor e, ultimamente, como diretor de escola, procurei entender como me tornei o diretor de escola que sou hoje, isto é, um diretor que procura, em suas ações, manter o estilo democrático de pensar e organizar a escola, com vistas à melhoria da qualidade do ensino.

Para caminhar sobre esta proposta, duas questões se fizeram necessárias: como na história de minha vida se constituiu a formação do diretor de escola pública estadual que sou hoje? E como me constituí como diretor com tendências democráticas, preocupado com a qualidade do ensino?

$\mathrm{Na}$ tentativa de responder às questões propostas, rememorei fatos de minha vida que se encontravam dispersos entre uma lembrança e outra, mas, mais que isto, fui percebendo que, verdadeiramente, nossa existência não se faz por acaso e nem mesmo sem propósito. Não quero dizer com isto que haja uma predeterminação que nos dirige, não, apenas acredito que escolhemos e estas escolhas nos abrem outras e novas possibilidades e cada uma dessas possibilidades nos conduz a novas escolhas e novas possibilidades. Acontece, porém, que na maioria das vezes não temos clareza de nossas escolhas, porque nos prendemos ao fato em si e não vislumbramos as possiblidades existentes de escolhas e suas possiveis consequências.

Hoje entendo que poderia ter feito outras escolhas, mas entendo ainda mais que, conforme o dito popular, não se chora leite derramado, e que outras escolhas possivelmente gerariam outros "eus", por isto, quero e tento viver o hoje que sou e que fui e me deixei construindo nesta "leveza" que é o humano. Entendo também, que as escolhas feitas eram possiveis e que, depois de feitas, cabe-me administrá-las e fazer outras possiveis.

Minha narrativa teve início com minha caminhada rumo à escola primária. Nesta primeira fase, procurei relatar minhas vivências como aprendiz do saber. Minha passagem pelo, então, grupo escolar, que se fez quase que desapercebida, mas que, ao refazê-la em minhas memórias, entendi que os saberes que me foram propostos não eram casuais, mas fruto de reflexões acadêmicas e tentativas de atender a um período histórico específico e peculiar, a ditadura militar brasileira. Segui o rumo da história e cursei o ginásio profissionalizante. Fiz e desfiz escolhas, cursei o colegial técnico agropecuário, trabalhei na área, desfiz esta escolha e fiz a de ser seminarista, cursei filosofia e teologia, desfiz a escolha clerical e mantive a filosofia.

Neste primeiro percurso de minha autobiografia, regia a educação a Lei de Diretrizes 
e Base (LDB), Lei 4.024 de 20 de dezembro de 1961, primeira lei nacional que passou a reger de forma orgânica a educação brasileira. Possuía uma visão inovadora de organização da educação, chamando a responsabilidade do educar para o Estado, em parceria com a família, e cuja pretensão era atender todos os brasileiros em idade escolar. Porém, a única menção que faz sobre o diretor de escola está em seu Artigo 42. "O Diretor da escola deverá ser educador qualificado", sem, contudo, especificar o que entendia por "qualificado" (BRASIL, 1961, Art. 42).

No entanto, não podemos esquecer que em 1964 tivemos o "Golpe Militar" e, sob o Regime Militar, as pretensões da LDB/1961 não conseguiram sair do papel; assim, em 11 de agosto de 1971, a LDB sofreu alterações com a promulgação da Lei 5.692, que, com forte espírito neoliberal, trouxe para a educação básica brasileira o eixo da formação para o trabalho, com as escolas técnicas de grau médio. Quanto à figura do diretor de escola, traz apenas que “A formação de administradores, [...] será feita em curso superior de graduação, com duração plena ou curta, ou de pós-graduação" (Art. 33), e que estavam garantidos os direitos dos diretores que ocupavam o cargo até então (BRASIL, 1971, Art. 84).

Evidente que reflexões acadêmicas sobre a administração escolar e a pessoa do administrador já eram preocupações entre os acadêmicos. Assim, figuras como Anísio Teixeira e José Querino Ribeiro, entre outros, despontam, buscando entender e elucidar o papel do administrador escolar e a sua formação.

Sob este pano de fundo, fiz minhas escolhas e trilhei meu caminho acadêmico sem perceber e entender tudo o que se passava na vida política e social à minha volta, mesmo porque poucos ousavam falar, criticar e se posicionar. Foi a filosofia que me ajudou a ver e ler as coisas com olhos diferentes, a pensar o mundo de forma mais crítica, mesmo porque, quando iniciei o curso universitário, a ditadura já perdera a força. No entanto, a mesma filosofia não me tirou a fé.

Fé que despontou em mim, ainda na infância, que cresceu comigo e me conduziu ao seminário. Fé que inicia e se firma em um Deus, mas que se realiza e concretiza nas pessoas, no próximo, no outro. A filosofia consolidou esta escolha pelo outro, pelo humano, mostrando-me caminhos, pois me ensinou a argumentar a favor dos seres humanos e, entre eles, os que são esquecidos socialmente, e a buscar a liberdade e a justiça social. Deu-me conhecimento, fez-me provar da cultura e fezme um pouco mais crítico. E então me fiz professor de filosofia.

Caminhei por minha escolha profissional por um tempo relativamente curto. Nele passei da escola pública para a particular e, da escola particular, de volta para a pública. Tentei entender a escola como ela é e como querem que ela seja. Entendi que políticas públicas não são feitas apenas para o bem comum, mas também para atender a ideologias sociais, econômicas e políticas; que o humano da classe menos favorecida nem sempre é olhado com os olhos merecidos, mas acaba se tornando peão no tabuleiro da vida.

Entendi também que neste jogo da vida não há inocentes ou culpados, há leituras incompletas ou parciais da realidade que nos impedem de fazer a diferença, que nos fazem olhar para aquilo que é menor ou de menor importância e, assim, perder a oportunidade de lutar pelo que de fato valia a pena.

Foi o que aconteceu, por exemplo, com a implantação da reforma educacional proposta pela Secretária de Estado da Educação Rose Neubauer, em 1998. Uma reforma autoritária, de cima para baixo, sem refletir e sem preparar a sua base. Com ela, Neubauer separou as escolas por niveis e promoveu a municipalização; 
organizou os níveis em ciclos e estes passaram a ser pensados enquanto progressão continuada, que ficou entendida por muitos como "promoção automática".

Na ocasião, nós, professores, ficamos preocupados com as perdas que teriamos com as mudanças. Pensávamos que os alunos seriam aprovados de um ano para o outro, independente da nota que lhes atribuíssemos e nossa preocupação foi: onde ficará nosso poder de controle? Pensando nisto, esquecemo-nos de ver o quanto a educação e, por ela, o quanto as crianças poderiam ser favorecidas se tivéssemos entendido e aproveitado aquilo que a lei nos propunha, e feito de nossas escolas espaços de aprendizagem compartilhada. Sim, compartilhada, como nos ensinou Freire (2014). E assim, lutando contra a ideologia dominante, caímos numa outra ainda maior e mais cruel, pois não nos preparando para atender com qualidade a camada social que passou a fazer parte dos bancos escolares, permitimos, dessa forma, a manutenção do status quo, deixamos que a qualidade do ensino se perdesse ao mesmo tempo em que as portas das escolas se abriam para atender a todos. Erro? Culpa? Não sei, digo apenas: escolhas. Esquecemos de Lima (2011) e não produzimos "regras alternativas", a favor do pedagógico.

No início de minha carreira de professor, vivenciei escolas nas quais acredito que o diretor nunca soube de minha existência e eu, com certeza, não soube da sua. Eu entrava e saía da escola observado por um inspetor de alunos que abria e fechava os portões e que a mim se dirigia com um "boa noite", dava minhas aulas e saía; desconhecia se nela havia um Coordenador Pedagógico, qual era seu Projeto Político Pedagógico e soube menos ainda de seu calendário escolar. Por outro lado, vivenciei escolas em que o diretor me recebeu no primeiro dia de aula, sentou comigo e dividiu suas preocupações, discutiu comigo meu plano de aula e se abriu para o novo que eu propus. Ensinou-me a ser professor.

Conheci igualmente diretor que apenas lamuriava o tempo passado, chorando as ditas "perdas" que a educação sofrera ao se renovar, contava os dias para se aposentar e ficar "livre disso"; diretor que no Conselho de Classe não percebia o aluno e nem muito menos aqueles que por ele clamavam, era amargo demais! Mas conheci diretor que se sentava como os professores nas Reuniões Pedagógicas, estudava conosco e nos apoiava e nos ensinava a ver o aluno como um todo, e não restrito a um ou outro saber acadêmico. Era acolhedor, paciente, chamava-nos à participação, sabia onde queria chegar, percebíamos em sua docilidade a firmeza de suas ações. Todas estas experiências permaneceram em minha memória e foram me constituindo.

De professor para diretor de escola foi um salto, embora conquistado, ímpar e ao mesmo tempo grandioso. É grandioso porque rompeu com a regra, fez do filho de barbeiro semialfabetizado, um estudante universitário, e não de uma universidade qualquer; fez igualmente dele, um professor e o fez diretor de escola.

Tenho certeza de que meu pai, se estivesse entre nós, vibraria muitíssimo com esta conquista que também é dele. É de meu pai também esta conquista, porque ele acreditou, ele impôs a seus filhos a condição e a paixão pelos estudos. Mas é de minha mãe também, pois ela sublimou sua vida para que nós tivéssemos as nossas com mais doçura, sem, contudo, nos iludir dos possiveis tropeços e quedas.

Minha experiência como diretor de escola teve início com minha posse no cargo, em junho de 1998. Cheguei à Escola Estadual Francisco Whitacker, município de Anhumas/SP, na época com cerca de 3,5 mil habitantes, temeroso e inseguro; dei meus primeiros passos sem saber ao certo o rumo que tomaria. Tinha mais dúvidas que certezas, na verdade as úni- 
cas convicções que trazia eram as que adquirira no caminhar de minhas estradas: é preciso ouvir e fazer junto.

O diálogo fez-se presente em mim, propusme a caminhar junto. Com o tempo, aprendi que minha posição de diretor me ajudaria a conquistar um caminho melhor e mais frutuoso para os que buscavam o conhecimento, então tateei caminhos sem saber ao certo quais eram. Experimentei situações que não imaginava dar conta.

Na Escola Francisco Whitacker, formamos um grupo de estudo com pais e funcionários, para entendermos as mudanças propostas pela SEE/SP, discutia com a Coordenação Pedagógica e com os professores nos Horários de Trabalho Pedagógico Coletivo (HTPC')

Em seguida, passei oito meses substituindo a direção na Escola Estadual Arruda Mello, de Presidente Prudente. Uma escola grande, central, com problemas múltiplos e diferentes dos que enfrentara na Escola Francisco Whitacker. Nela encontrei problemas relacionados com as drogas e com a violência; sentei-me com os alunos para discutirmos como se daria a convivência dos grupos com diferentes manifestações afetivas e tratamos, desde o simples uso dos banheiros, até a forma de manifestarmos nossos afetos no espaço escolar. Diálogo que produziu resultados porque foi fruto de acordo coletivo entre os alunos. Nesta mesma escola, tivemos que quebrar a barreira do diálogo com as famílias. Por ser uma escola central, que atendia a mais de 190 bairros da cidade, na maioria bairros periféricos e de famílias de baixa renda, o diálogo e a comunicação acontecia de forma muito precária, e os alunos acabavam esquecidos e deixados ao abandono da evasão. Fizemos um grande mutirão, chamamos os pais dos evadidos e faltosos e passamos uma semana atendendo a estes e, como

1 Hoje usa-se a sigla de ATPC - Aula de Trabalho Pedagógico Coletivo. resultado, conseguimos resgatar boa parte dos alunos tidos como evadidos. No entanto, faltou o meu olhar para o pedagógico, faltou o sentar com mais vagar com o professor, para juntos caminharmos.

Depois da Escola Arruda Mello, voltei para Anhumas, mas poucos meses depois fui convidado para dirigir o CEFAM (Centro de Formação e Aperfeiçoamento do Magistério), novamente em Presidente Prudente. Neste, os problemas sociais eram menores e os administrativos pequenos. Porém, o desafio pedagógico era gigantesco. Eu que aprendi a ser diretor administrativo, agora precisava aprender a ser pedagógico. Caminhei lentamente, mas a cada reunião pedagógica aprendia um pouco mais. A cada aprendizado surgiam novas possibilidades, novas dúvidas, mas também novos quereres e novos desejos de fazer e fazer melhor.

O projeto CEFAM foi encerrado pelo governo do Estado de São Paulo, em 2005, e, depois de passar alguns meses adido na Diretoria de Ensino de Presidente Prudente, fui, finalmente, removido ex officio para a EE Francisco Pessoa.

A Escola Francisco Pessoa está localizada no bairro Ana Jacinta de Presidente Prudente, a cerca de $10 \mathrm{~km}$ do centro da cidade. Esse bairro nasceu de um conjunto habitacional popular e se agigantou. Uma boa parte dos que ali habitam são pessoas simples e de baixa renda, mantém suas casas no mesmo formato inicial; outros, no entanto, conseguiram se sobressair na labuta da vida e remodelaram suas casas, mantendo seu carro na garagem e a estabilidade trabalhista. No entanto, e talvez por isso, o bairro era tido como "dormitório", as famílias saíam cedo para o trabalho no centro da cidade e voltavam já ao cair da noite. Com poucos afazeres, as crianças e adolescentes ficavam à mercê das ruas.

Cheguei à escola ansioso, evidentemente, um frio perpassava minha barriga, mas não temia, como temi ao chegar em Anhumas; tinha 
convicções mais amadurecidas, mesmo assim não fui afoito. Passei alguns meses analisando e conhecendo a escola, seus alunos, os professores, os funcionários e a comunidade. Ouvi muito mais do que fiz, até que, com uma equipe de trabalho mais afinada nos mesmos ideais, comecei a agir e não mais separava o administrativo do pedagógico. Eu era diretor de escola e administrar o espaço escolar fazia parte deste ser, assim como o pedagógico, cada uma dessas atividades no seu momento e na sua necessidade. Mesmo que em muitas situações estes momentos se confundissem e se juntassem, tornando-se únicos. Ajudavam-me na administração o vice-diretor e a secretária, no pedagógico, os professores coordenadores.

A equipe da Escola Francisco Pessoa tornou-se coesa, tínhamos convicções muito próximas, lutávamos por ideais parecidíssimos e a aprendizagem de nossos alunos era a pauta de nosso dia a dia. É certo que havia desavenças, vez ou outra, nos deparávamos com situações, problemas com professores que não se juntavam ao pensamento do grupo, alunos que destoavam completamente do contexto e que já haviam feito suas opções por outros caminhos. Mas, apesar disto e por isto, o grupo era coeso não só no trabalho escolar, mas também nos horários de lazer.

Nesta escola, não conseguimos que o grêmio estudantil se fortificasse, mas por um espaço de tempo razoável conseguimos reunir a escola e a comunidade e discutimos as preocupações comuns. Conseguimos, ainda, uma parceria com a universidade, que refletiu conosco em ATPC as dificuldades do processo educacional.

No entanto, mudar fez-se necessário e aqui estou na Escola Estadual Prof. Arlindo Fantini, uma escola que se localiza num bairro próximo ao centro da cidade, mas marcado por uma grande diferença social, indo da pobreza extrema à folgada estabilidade econômica, mas os problemas que afligem as crianças e os adolescentes são os mesmos encontrados no bairro de Ana Jacinta.

Cheguei nesta escola por opção, em 2011, mas não por gosto, parte de mim ainda pertencia à Escola Francisco Pessoa, porém não estava arrependido. Já contava com treze anos como diretor de escola e com a experiência de quatro diferentes escolas, por isso fui menos cauteloso e temeroso. Assim, atendi de pronto o administrativo que precisava de acertos severos, mas caminhei com o pedagógico, ouvindo e refletindo com os alunos e os professores.

o exercício democrático que sempre busquei praticar durante minha caminhada, passou por seu mais frágil momento, pois havia situações que exigiram mudanças urgentes, pois se tratava de questões éticas e legais.

Aqui, como na Escola Francisco Pessoa, também formamos uma equipe gestora que trabalha bastante afinada, o que não quer dizer que concordamos em tudo, mas colocamos tudo em discussão e só então em prática. Pela primeira vez, consegui um Grêmio Estudantil atuante, que trabalha em concordância com os interesses dos alunos e, quando a situação pede, se junta à gestão para um trabalho conjunto e de equipe.

Com o passar do tempo, os afazeres administrativos reduziram-se à normalidade e pudemos dar maior ênfase ao pedagógico. Com a nova equipe, o trabalho pedagógico ficou mais organizado e estruturado; os resultados das avaliações realizadas nos finais de ano foram visiveis. Pais, alunos e professores constataram estas mudanças e a elas são favoráveis.

Conseguimos manter bom diálogo e cumplicidade como os pais. Durante as reuniões periódicas de pais conseguimos boa frequência e participação dos mesmos. Um grupo menor trabalha com a gestão, discutindo os problemas da escola e ajudando em sua organização. Não é um trabalho fácil e nem flui 
como desejaríamos, mas acontece com relativa frequência e bons resultados. A equipe pedagógica reúne-se semanalmente para afinar a caminhada semanal, juntos estão o grêmio, a secretaria e a mediação.

As trocas entre os pais e o pedagógico são ainda maiores e mais intensas. Sempre que uma parte está com um problema procura a outra, nenhum pai sai sem ser ouvido e sem ter uma explicação razoavelmente satisfatória. Há falhas, sim, pois limitados pelo número de funcionários, não conseguimos atender e dar conta de todos os afazeres, portanto, não conseguimos acompanhar de perto as aulas dos professores para dar-lhes o suporte que precisam para melhor desenvolverem o seu trabalho. 0 noturno ainda conta com um olhar debilitado de nossa parte e ele se perde com um número significativo de alunos evadidos e retidos.

Percebi, ao longo de minhas pesquisas, que tanto o Conselho de Escola quanto a Associação de Pais e Mestres (APM) são instituições e agremiações que podem contribuir com o trabalho pedagógico e tornar as discussões e afazeres escolares mais democráticos. Não sei responder o porquê, porém, em minha caminhada como diretor de escola, nunca consegui me familiarizar muito com estes dois segmentos escolares, ou pela burocracia para reuni - los ou, mais provável, por não ter entendido suas contribuições reais. No entanto, é preciso salientar que, embora sejam caminhos que podem nos conduzir ao exercício democrático, não são únicos, porém são instituídos e reconhecidos legalmente, por isso precisam ser aproveitados.

Entendemos que, embora pareçam poucos, o exercício democrático foi acontecendo ao longo da caminhada através dos encontros que fazemos mensalmente com os diversos segmentos da escola. Encontros estes em ATPC e em planejamento, de forma coletiva, ouvindo e refletindo com alunos e pais de alunos.
Encontros quinzenais com os líderes de sala para discutir caminhadas. Reuniões corriqueiras com o Grêmio Estudantil e semanais com a equipe pedagógica. Acreditamos que todos estes são espaços de construção do coletivo e, portanto, exercícios de uma gestão que se pretende democrática.

Finalmente, passados sete anos de trabalho, posso dizer que o diálogo foi restabelecido, caminhamos construindo juntos. Pelas falas e avaliações realizadas pela escola, junto à comunidade, percebemos que o caminho está sendo construído no e pelo exercício democrático e com vista a uma educação de maior qualidade. Percebemos também que a democracia não é um instante ou uma ideia, mas um exercício diário do aprender a ser. Meu ser diretor é muito mais fruto do exercício do ofício do que dos bancos acadêmicos, e se faz, igualmente, no dia a dia da escola, nas trocas, nos erros e acertos.

\section{Algumas Considerações}

Depois de debruçar-me neste estudo, percebo que ainda há muito a ser feito, por mais que entenda ser minha caminhada uma busca por educação de qualidade para todos, por meio do exercício democrático, ainda há muito a ser feito, pois o exercício democrático se faz no caminhar, no refletir conjuntamente e juntos construir. É certo que há momentos de decisões isoladas, sem dúvida, isto faz parte de minhas funções, mas, se eu estiver em sintonia com a equipe da escola e a equipe da escola em sintonia comigo, estas decisões serão muito próximas do pensar do grupo.

Igualmente é o ser diretor de escola. Não se faz um diretor de escola apenas nos bancos acadêmicos, mas também não se faz um diretor sem estes saberes. 0 saber acadêmico e pedagógico é extremamente necessário e nos permite encurtar caminhos e facilitar as 
escolhas e decisões. Porém, o saber sem a realidade, sem o dia a dia, sem o chão da escola, não produz os efeitos desejados. Ser diretor de escola é uma construção que se faz cotidianamente, na leitura diária da escola e dos problemas reais que nela se apresentam.

No saber que fui construindo para chegar à dissertação de mestrado, percebi que minha caminhada, embora tenha produzido bons frutos e tenha elementos democráticos, precisa de ajustes e direcionamentos em busca de posições de fato democráticas. É preciso rever meu posicionamento junto ao Conselho de Escola e à APM. É preciso continuar ouvindo os grupos, com assiduidade, e aprender a partilhar as escolhas, anseios e desejos deles. É preciso aprender a confiar mais e delegar mais.

Nos relatos da equipe com a qual partilho o trabalho na escola, percebo que estamos caminhando de forma acertada, percebo também que alguns poucos não sabem exatamente o que é ou como é o processo democrático, mas concordam com a forma como caminhamos. Outros tantos, mais conscientes do fazer pedagógico, compartilham, comungam e buscam caminhar nesta mesma toada. Com mais segurança e de forma crescente, pais e alunos compartilham conosco seus desejos e se juntam a nós, no fazer a escola, e nosso grupo vai se tornando qualitativamente maior e melhor.

Quanto às questões levantadas e que deram o impulso necessário a estas reflexões, creio que posso afirmar com segurança: não sou fruto do acaso, nem muito menos do destino, me fiz ao longo de minhas experiências de vida e, à medida que fui me fazendo, meus olhares foram se transformando, fui aprendendo a ler os fatos e a história com outros olhares e assim me constituí no diretor de escola que hoje sou, isto é, um diretor que possui convicções democráticas e crê que, através do trabalho coletivo, se chega à educação de melhor qualidade para todos.
Nesta caminhada, alguns saberes foram me constituindo e me fazendo o diretor de escola que sou.

Desses saberes ficam, ser diretor é ...

... sonhar.

... participar da utopia.

... buscar constante.

... lutar contra o tempo.

... conviver com a ilusão da autonomia.

... viver na corda bamba entre os valores e as necessidades de alunos e professores.

... não se deixar encantar pelos pequenos poderes.

... fazer valer o direito de todos.

... cumplicidade e democracia, não de forma barata.

... não esquecer que a escola é para o aluno.

... articular as divergências de interesses de pais, alunos e professores.

... não sucumbir ao encanto do populismo com professor e aluno.

... querer ver através e além da cortina.

... lutar contra o estabelecido.

... incorporar as críticas.

... saber ouvir.

... agir na urgência, decidir na incerteza.

... viver a luta entre a passividade e a participação.

... descentralizar sem se omitir.

... administrar a dimensão normativa em benefício do coletivo da escola.

Muitos caminhos podem nos levar ao mesmo lugar, mas cada pessoa tem suas marcas pessoais ao cruzar os seus próprios caminhos. Por isso a causalidade é precária, ela não dá conta da leveza do ser, porém, é nessa leveza do ser que se dá a resistência dos que almejam uma educação de qualidade para todos.

\section{Referências}

ABRAHÃO, Maria Helena Menna Barreto. Metamemória-memórias: memoriais rememorados/narrados/ 
refletidos em Seminário de Investigação-Formação. In: PASSEGGI, Maria da Conceição; BARBOSA, Tatyana Mabel Nobre. (Orgs.). Memórias, memoriais: pesquisa e formação docente. Natal: EDUFRN; São Paulo: Paulus, 2008. p. 153-176. [Coleção Pesquisa (Auto) Biográfica \& Educação].

BEISIEGEL, Celso de Rui. Relações entre a quantidade e a qualidade no ensino comum. In: BEISIEGEL, Celso de Rui. A qualidade do ensino na escola pública. Brasília, DF: Líber Livro Editora, 2005. p. 111-122.

BEISIEGEL, Celso de Rui. Política educacional e programas de alfabetização. Ideias - A educação básica no Brasil e na América Latina: repensando sua história a partir de 1930, n. 1, p. 16-22, 1988.

BOSI, Ecléa. Memória e sociedade: lembranças de velhos. 18. ed. São Paulo: Companhia das Letras, 2015.

BRASIL. Lei no 4.024, de 20 de dezembro de 1961. Fixa as Diretrizes e Bases da Educação Brasileira. Disponível em: <http://www.planalto.gov.br/ccivil_03/leis/L4024.htm>. Acesso em: 29 mar. 2019.

BRASIL, Lei no 5.692, de 11 de agosto de 1971. Reorganiza o Ensino de 1으 e 2 o graus. Disponível em: <http:// www.planalto.gov.br/ccivil_03/leis/L5692. htm>. Acesso em: 29 mar. 2019.

BRASIL. Constituição da República Federativa do Brasil de 1988. São Paulo: Imprensa Oficial, s.d.

BRASIL. Lei no 9.394, de 20 de dezembro de 1996. Estabelece as diretrizes e bases da educação nacional. Diário Oficial da União, 23 dez. 1996. Seção 1, p. 207.

BRASIL. Lei no 13.005, de 25 de junho de 2015. Aprova o Plano Nacional de Educação - PNE e dá outras providências. Diário Oficial da União de 26.6.2014 Edição extra.

CORTELLA, Mário Sérgio. A escola e o conhecimento - Fundamentos epistemológicos e políticos. São Paulo: Cortez, 1998.

DI GIORGI, Cristiano Amaral G.; LEITE, Yoshie Ussami Ferrari. A qualidade da escola pública, na perspectiva democrática e popular. Série-Estudos: Periódi- co do Programa de Pós-Graduação em Educação da UCDB, Campo Grande, MS, n. 30, p. 305-323, jul./ dez. 2010.

FERREIRA FILHO, João. A escola pública e a formação do diretor: uma narrativa autobiográfica. 2016. 282 f. Dissertação (Mestrado em Educação) - Universidade Estadual Paulista, FCT-Unesp, Presidente Prudente, SP, 2016.

FREIRE, Paulo. Pedagogia do oprimido. 58. ed. rev. e atual. Rio de Janeiro: Paz e Terra, 2014.

JOSSO, Marie-Christine. Os relatos de histórias de vida como desvendamento dos desafios existenciais da formação e do conhecimento: destinos sócio-culturais e projetos de vida programados na invenção de si. Tradução de Denice Barbara Catani. In: SOUZA, Elizeu Clementino de.; ABRAHÃO, Maria Helena Menna Barreto. (Orgs.). Tempos, narrativas e ficções: a invenção de si. Porto Alegre: EDIPUCRS, 2006. p. 21-40.

LIBÂNEO, José Carlos; OLIVEIRA, João Ferreira de.; TOSCHI, Mirza Seabra. Educação Escolar: políticas, estrutura e organização. 10. ed. revista e ampliada. São Paulo: Cortez, 2012.

LIBÂNEO, José Carlos. Organização e gestão escolar: teoria e prática. 6. ed. revista e ampliada. São Paulo: Heccus Editora, 2015.

LIMA, Licínio Carlos Viana da Silva. A escola como organização educativa: uma abordagem sociológica. 4. ed. São Paulo: Cortez, 2011.

NÓVOA, António. Para uma análise das instituições escolares. In: NÓVOA, António (Org.). As organizações escolares em análise. Lisboa: Instituto de Inovação Educacional, 1995. p. 15-43.

PARO, Vitor Henrique. Administração escolar: introdução crítica. 16. ed. São Paulo: Cortez; Autores Associados, 2010.

PARO, Vitor Henrique. (Org.). Administração Escolar: à luz dos clássicos da pedagogia. São Paulo: Xamã, 2011.

Recebido em: 27/08/2017 Aprovado em: 11/03/2019 
João Ferreira Filho é doutorando e Mestre em Educação pela Universidade Estadual Paulista - FCT-Unesp de Presidente Prudente. Diretor efetivo de Escola Pública estadual no Estado de São Paulo. Membro do Grupo de Pesquisa Formação de Professores, Políticas Públicas e Espaço Escolar. e-mail: joaoffilho23@gmail.com

FCT-Unesp de Presidente Prudente - Rua Fagundes Varela, 457 - CEP 19.020-620- Vila Lessa - Presidente Prudente-SP. Fone: 18-99742-0088

Yoshie Ussami Ferrari Leite é Doutora em Educação pela Universidade Estadual de Campinas, com Estágio de PósDoutoramento em Educação na Universidade de São Paulo. Professora Adjunta do Departamento de Educação e do Programa de Pós-graduação em Educação da FCT/Unesp/Campus de Presidente Prudente. Líder do Grupo de Pesquisa Formação de Professores, Políticas Públicas e Espaço Escolar (GPFOPE). e-mail: yoshie.leite@unesp.br

FCT-Unesp de Presidente Prudente - Rua Eufrásio de Toledo, 206 - CEP 19.606-100 - Jardim Marupiara - Presidente Prudente-SP. Fone: 18-99771-5720 